\title{
Screening Colonoscopy in Older Patients: Elder Care or Elder Abuse?
}

\author{
Pedro Costa-Moreira ${ }^{1,2} \cdot$ Marco Silva $^{1,2}$
}

Published online: 20 January 2020

(c) Springer Science+Business Media, LLC, part of Springer Nature 2020

Colorectal cancer (CRC) is the second-most leading cause of cancer-related mortality and the fourth-most commonly diagnosed malignant disease worldwide [1]. Though colonoscopy is one of the primary screening modalities for colorectal cancer, to justify its risks and costs, its effectiveness should be substantially higher than its alternatives [2]. Although well-established quality indicators exist such as adenoma detection rate, cecal intubation rate, and quality of the bowel preparation, the ability to detect unsafe practice remains underreported. Another concern is the occurrence of a chain effect due to procedural complications that will increase the frequency of hospitalization, follow-up, and total costs related to the procedure [3].

Knowledge of the harm caused by colonoscopy in routine practice is therefore crucial for decision makers in health policy. Recently proposed quality indicators have suggested appropriate performance targets for adverse events. According to the American Society for Gastrointestinal Endoscopy/ American College of Gastroenterology Task Force on Quality in Endoscopy, post-polypectomy bleeding occurs in $<1 \%$ of cases. The incidence of perforations is $<1: 500$ for all examinations and $<1: 1000$ for screening [4]. The European Society of Gastrointestinal Endoscopy (ESGE) also recommends appropriate rates for colonoscopy-related adverse events of $<5 \%$ for bleeding and $<1: 1000$ for perforations [5].

Hospital visits are generally unexpected after outpatient colonoscopy. Previous reports showed that hospital visit rates after outpatient colonoscopy range from 0.8 to $3.8 \%$, based on the outcomes measured such as admissions alone, admissions following emergency department visits, or hospital visits for specific complications, and a time frame for measurement after colonoscopy (i.e., 7, 14, or 30 days

Marco Silva

marcocostasilva87@gmail.com

1 Gastroenterology Department, Centro Hospitalar e Universitário São João, Al. Prof. Hernâni Monteiro, 4200-319 Porto, Portugal

2 Faculty of Medicine, University of Porto, Porto, Portugal post-procedure) [2, 6-8]. Clinicians performing colonoscopies underestimate these clinical outcomes, in part because they may not be aware when their patients seek follow-up care from other providers in settings such as hospital emergency departments.

Though data associating overall adverse events related to colonoscopy and age are debated, data about specific complications yield firmer conclusions. Although minor complications associated with colonoscopy such as such as bloating and abdominal pain are not influenced by age [6], major adverse outcomes such as perforation, bleeding, and cardiovascular/pulmonary complications may be influenced in part by age [9]. Despite the increase in several adverse events, age contributes to a number of other factors related to the prevalence and characteristics of colonic polyps. Elderly patients have larger sized and more proximally located adenomatous polyps which may lead to higher rates of colorectal cancer in this population [10]. Also, a greater prevalence of diverticulosis, more tortuous colons, higher rates of obstructing CRC resulting, and a greater probability of polyps requiring therapeutic intervention all occur more frequently in older patients, and since all of these increase the technical difficulty of colonoscopy, they are possible explanations for this increased risk [2]. The rapid increase in the median age of the population coupled with prolonged life expectancy has increased the number of colonoscopies performed in the elderly population that in turn burdens the healthcare system, with increased medical expenses and questionable cost-effectivity.

As part of a complex equation, the decision about when to discontinue screening of colorectal cancer should be individualized based on shared decision making, considering the patient's risk for colorectal cancer, prior screening history, personal values, and whether the patient's comorbid conditions and life expectancy justify the risks and inconveniences of continued screening. Although screening at least until age 75 years for patients at average risk for CRC is recommended by most guidelines, the data regarding screening in older aged patients are more heterogenous. The US Preventive Services Task Force (USPSTF) strongly recommends 
screening colonoscopy in average-risk, asymptomatic adults aged 50-75, consideration of colonoscopy based on comorbidity and prior screening for patients age 76-85, and against screening colonoscopy after age 85 [11].

A systematic review [2] showed that patients $\geq 80$ years undergoing colonoscopy experienced higher rates of cumulative adverse events (incidence rate ratio 1.7 ; 95\% CI 1.5-1.9) and had a greater risk of perforation (incidence rate ratio $1.6,95 \%$ CI 1.2-2.1) compared with younger patients. Also, there was a statistically insignificant trend toward higher rates of gastrointestinal bleeding and cardiovascular/pulmonary complications in octogenarians. Regarded in another way, the incidence of mortality after a colonoscopy remains very small. Despite these data, some reports have shown that colonoscopy in the very elderly can be performed safely and successfully. According to the latest guidelines regarding endoscopic practice for the elderly, one of the key means of minimizing risk in elderly patients is to perform endoscopy with minimal or no sedation [12].

Multiple previous studies have found increasing risks of serious post-colonoscopy adverse events with increasing age, but most previous studies have not directly compared different age classes. In an attempt to further study the predictors of unplanned emergency department (ED) visits and hospitalization following outpatient colonoscopy, Grossberg et al. [13] in this issue of Digestive Diseases and Sciences retrospectively reviewed 61,956 outpatient screening or surveillance colonoscopies in patients $\geq 50$ years in a tertiary center. The authors reported that ED visits occurred within 7 days following $188(0.62 \%)$ colonoscopies. This study showed that patients aged over 75 years were more likely to have an ED visit [OR 1.6 (95\% CI 1.05-2.38)] and hospitalization [OR 3.7 (95\% CI 2.03-6.72)] within 7 days of outpatient colonoscopy, with age $>75$ years was the strongest predictor of mortality following colonoscopy. Despite the increased overall comparative risk, the absolute numbers remain quite small in this age group: $0.01 \%$ for ED visits and $0.007 \%$ for hospitalizations.

Other variables associated with an increased risk of ED visit were also intrinsically associated with an increased age (recent ED visit and higher number of medications classes, and endoscopic intervention such as polypectomy or endoscopic mucosal resection). Furthermore, mortality after colonoscopy is strongly associated with increasing age: $15 \%$ of patients $>85$ years died within 8 years of colonoscopy compared to $<2 \%$ of patients aged $<75$ years, giving a 5 -year cumulative mortality probability of $19.5(0.042)$ for patients $>85$ and $2.2(0.001)$ for patients aged 50-75. The authors concluded that based on this finding, routine screening or surveillance colonoscopy should be discussed and carefully evaluated in patients of advanced age. Nevertheless, the authors noted that the major challenge of using this study to define when cancer screening should no longer be offered is that these models cannot address the heterogeneity of life expectancies in the older population in which some individuals have several years of life expectancy, while others have very little.

While data support weighing benefits and harms in older adults and using a personalized approach, patients are generally resistant to screening cessation. Fear of cancer, hope for early detection and treatment, family history, obligation, and reassurance are all factors that patients report for their desire to continue colorectal cancer screening, even in situations of augmented risk. It is crucial to use a consistent definition and refined data worldwide to identify and compare adverse events. Future studies should use a uniform definition for post-colonoscopy complications. When complications occur, use of standardized systems and recording methods are required to enable structured monitoring and reviewing parameters such as type of complication, cause of occurrence, and treatment method.

In conclusion, appropriate patient selection and preparation are essential for all endoscopic procedures since it contributes significantly to the safety and success of the procedure. In addition to the proper explanation about what the procedure entails, it is also necessary to explain potential risks and complications as part of the consent process so that in particular elderly patients can make informed decisions regarding a pending procedure.

Funding There is no funding declaration.

\section{Compliance with Ethical Standards}

Conflicts of interest All authors disclosed no personal conflicts of interest or financial relationships relevant to this publication.

\section{References}

1. Ferlay JF. GLOBOCAN 2000. Cancer incidence, mortality and prevalence worldwide, Version 1.0 IARC Cancerbase; 2001.

2. Day LW, Kwon A, Inadomi JM, Walter LC, Somsouk M. Adverse events in older patients undergoing colonoscopy: a systematic review and meta-analysis. Gastrointest Endosc. 2011;74:885-896.

3. Kim SY, Kim HS, Park HJ. Adverse events related to colonoscopy: global trends and future challenges. World J Gastroenterol. 2019;25:190-204.

4. Rex DK, Schoenfeld PS, Cohen J, et al. Quality indicators for colonoscopy. Am J Gastroenterol. 2015;110:72-90.

5. Rembacken B, Hassan C, Riemann JF, et al. Quality in screening colonoscopy: position statement of the European Society of Gastrointestinal Endoscopy (ESGE). Endoscopy. 2012;44:957-968.

6. Ko CW, Riffle S, Shapiro JA, et al. Incidence of minor complications and time lost from normal activities after screening or surveillance colonoscopy. Gastrointest Endosc. 2007;65:648-656. 
7. Leffler DA, Kheraj R, Garud S, et al. The incidence and cost of unexpected hospital use after scheduled outpatient endoscopy. Arch Intern Med. 2010;170:1752-1757.

8. Chukmaitov AS, Menachemi N, Brown SL, Saunders C, Tang A, Brooks R. Is there a relationship between physician and facility volumes of ambulatory procedures and patient outcomes? J Ambul Care Manag. 2008;31:354-369.

9. Forsberg A, Hammar U, Ekbom A, Hultcrantz R. A register-based study: adverse events in colonoscopies performed in Sweden 2001-2013. Scand J Gastroenterol. 2017;52:1042-1047.

10. Singal AK, Rosman AS, Post JB, Bauman WA, Spungen AM, Korsten MA. The renal safety of bowel preparations for colonoscopy: a comparative study of oral sodium phosphate solution and polyethylene glycol. Aliment Pharmacol Ther. 2008;27:41-47.

11. Bibbins-Domingo K, Grossman DC, Curry SJ, et al. Screening for colorectal cancer: US preventive services task force recommendation statement. JAMA. 2016;315:2564-2575.
12. Qureshi WA, Zuckerman MJ, Adler DG, et al. ASGE guideline: modifications in endoscopic practice for the elderly. Gastrointest Endosc. 2006;63:566-569.

13. Grossberg LB, Papamichael K, Leffler DA, Sawhney MS, Feuerstein JD. Patients over age 75 are at increased risk of emergency department visit and hospitalization following colonoscopy. Dig Dis Sci. (Epub ahead of print). https://doi.org/10.1007/s1062 0-019-05962-3.

Publisher's Note Springer Nature remains neutral with regard to jurisdictional claims in published maps and institutional affiliations. 